\title{
De la pólis al Estado moderno: una aproximación al problema de lo político en Heidegger
}

\section{From the pólis to the modern state: an approach to the problem of politics in Heidegger}

\author{
Paloma Martínez Matías \\ Universidad Complutense de Madrid \\ palomamartinezm@filos.ucm.es
}

Recibido: 19/10/2014

Aceptado: 08/03/2015

\section{Resumen}

Este trabajo parte de la pregunta por la posibilidad de deducir un planteamiento estrictamente político de los análisis ontológicos de la modernidad llevados a cabo por Martin Heidegger. Con este fin, se examina su interpretación del fenómeno griego de la pólis, así como la distinción que en ella se establece entre esta forma de comunidad y el Estado moderno, fundado para Heidegger en la esencia metafísica de la modernidad. Para clarificar esta cuestión se atiende a la proclamación de valores que Heidegger observa en los diferentes modos de organización estatal que aparecen en la época de la consumación técnica de la metafísica. En conexión con ello, se estudia su visión del nihilismo y se ofrece finalmente una hipótesis sobre la forma de Estado que resultaría coherente con la renuncia a los valores que, a su juicio, exige la manifestación del ente en la modernidad como objeto por entero producible.

Palabras clave: comunidad, metafísica, Nietzsche, nihilismo, ontología, política, valor.

\begin{abstract}
This paper starts off asking whether a strictly political approach may be deduced based on Martin Heidegger' ontological analyses of modernity. His interpretation of the Greek phenomenon of the polis is discussed along with the distinction established therein between this form of community and the modern state, founded according to Heidegger on the metaphysical essence of modernity. To clarify this question regard is had to the proclamation of values observed by Heidegger in the
\end{abstract}


different forms of state organization arising in the age of technical consummation of metaphysics. In this connection, his vision of nihilism is studied and a hypothesis is finally offered as to the form of state that would be consistent with a renunciation of the values required, in his view, by the manifestation of the entity in modernity as a wholly producible object.

Keywords: community, metaphysics, Nietzsche, nihilism, ontology, politics, value.

\section{Introducción: lo político en Heidegger}

La afirmación de que el pensamiento de Heidegger no es ajeno a lo político ha cobrado significados muy diversos e incluso abiertamente contradictorios desde que comenzara el debate hermenéutico en torno a su obra. La ambigüedad que se abre en su potencial multiplicidad de sentidos reposa ciertamente sobre la previa constatación de que su proyecto filosófico excluye de facto toda tematización expresa y programáticamente elaborada sobre asuntos de índole política. Pero es sin duda su compromiso con el nacionalsocialismo a partir de 1933, año en que Heidegger acepta el cargo de Rector de la Universidad de Friburgo e ingresa en el partido nazi, lo que no ha dejado de suscitar toda suerte de interrogantes y polémicas más o menos enconadas acerca del posible carácter político de la reflexión ontológica que alienta cada uno de sus textos.

La inexcusable necesidad de atender a la gravedad del enredo del filósofo con un movimiento político de ideología tan inquietante como nefasta en sus bien conocidas consecuencias ha vertebrado esta problemática en al menos dos líneas de investigación -y aquí el esfuerzo de síntesis es inevitablemente simplificador- que, a nuestro juicio, responden a dos actitudes en principio opuestas frente al legado heideggeriano. En la primera de ellas se amalgaman intentos de diferente índole por probar que, lejos de representar un error fortuito del "ciudadano" Heidegger, su apuesta por el nacionalsocialismo hundiría sus raíces en el núcleo más íntimo de su pensamiento incluso desde antes de la publicación de Ser y tiempo e impregnaría de manera velada, aunque no por ello irreconocible, la totalidad de su despliegue ${ }^{1}$. Sobre esta posición se ha lanzado la sospecha de fundarse sobre el discutible supuesto de que tal demostración nos autorizaría a prescindir definitivamente de la filosofía de Heidegger, exonerándonos así de la tarea de enfrentarnos a las espinosas y turbadoras preguntas que en sus textos se perfilan en torno a aspectos cruciales de nuestra actualidad y de su creciente tecnificación ${ }^{2}$. En claro conflicto con esta línea,

\footnotetext{
${ }^{1}$ En esta línea, y entre la numerosa bibliografía existente, cabe mencionar los trabajos de V. Farías. Heidegger y el nazismo. Barcelona: Muchnik, 1989; E. Faye. Heidegger. La introducción del nazismo en la filosofía. En torno a los seminarios inéditos de 1933-1935. Madrid: Akal, 2009; J. Fritsche. Historical Destinity and National Socialism in Heidegger's Being and Time. California: University of California Press, 2009.

${ }^{2}$ Cfr. S. Zizek. En defensa de causas perdidas. Madrid: Akal, 2011, p. 123.
} 
la segunda reúne propuestas que, sin rehuir el asunto de la conexión del pensamiento de Heidegger con su adhesión personal al nacionalsocialismo, se han centrado en defender, aun adoptando perspectivas notablemente distintas, que su obra posterior a 1934 -fecha en la que abandona el Rectorado- se construye sobre la base de una prolongada confrontación crítica con este movimiento. Desde esta premisa y con resultados asimismo dispares, este enfoque ha destacado la importancia de tal confrontación para entender no sólo el sentido de la trayectoria heideggeriana, sino también la naturaleza misma del nazismo en función de la singular luz que, siempre de forma indirecta pero igualmente reconocible, en ella se arroja sobre este fenómeno político. Pues si bien la exclusividad de su dedicación a la pregunta por el ser habría eludido que semejante controversia se sostuviera en el plano de lo que estrictamente podría conformar una teoría política, su investigación no carecería de implicaciones para la reflexión filosófica de lo político de innegable validez para el presente 3 .

Una cuestión que, sin embargo, no ha recibido tal vez suficiente consideración en esta segunda posición es la que incide en la posible deriva de un planteamiento rigurosamente político a partir de los rendimientos ontológicos emergentes de lo que Heidegger valoraría como «el fracaso del Rectorado» ${ }^{4}$. En los meses posteriores a su renuncia al cargo de Rector, su obra se muestra marcada por el inicio de un doble diálogo, en primer lugar con la poesía de Hölderlin y, poco después, con el pensamiento de Nietzsche. Frente a la imagen parcialmente globalizadora de la historia de la ontología que se desprende de Ser y tiempo, ello le conducirá a una renovada visión de la modernidad -término que Heidegger hace extensivo a nuestra actualidad histórica-que habrá de definirla complejamente tanto por su origen griego como por el decisivo vuelco con respecto a Grecia que forja la dinámica de su constitución. En este momento de la indagación ontológica heideggeriana se torna entonces esencial la pretensión de delimitar conceptualmente el modo en que las cosas comparecen o son en la modernidad en su dependencia y al mismo tiempo radical diferencia frente a aquél que determina su presencia en Grecia. Como revela la serie de escritos privados cuya redacción Heidegger comienza en $1936^{5}$, en el marco de esta tarea

\footnotetext{
${ }^{3}$ También a modo de ejemplo citaremos en este caso las obras de R. Schürmann. Le principe d'anarchie: Heidegger et la question de l'agir. París: Seuil, 1982; S. Vietta. Heideggers Kritik am Nationalsozialismus und an der Technik. Tübingen: Niemeyer, 1989; D. Janicaud. L'ombre de cette pensé - Heidegger et la question politique. Grenoble: J. Millon, 1990; P. Lacoue-Labarthe. La imitación de los modernos (Tipografias II). Buenos Aires: La Cebra, 2010, y La ficción de lo político. Madrid: Arena Libros, 2002; M. de Beistegui. Heidegger y lo político. Buenos Aires: Prometeo Libros, 2013.

${ }^{4}$ Carta de Heidegger a Karl Jaspers del 1 de Julio de 1935, en M. Heidegger-K. Jaspers. Briefwechsel 1920-1963. München: Piper, 1992, p. 157. Excepciones a este respecto las constituirían, entre otras, la citada obra de R. Schürmann y los trabajos de A. Leyte. Heidegger. Madrid: Alianza, 2005, y F. Martínez Marzoa. «La palabra que viene», en F. Duque (Comp.). Heidegger: la voz de tiempos sombrios. Barcelona: Serbal, 1991, pp. 147-160.

${ }^{5}$ Nos referimos a la serie de textos que Heidegger escribe entre 1936 y 1942 sin intención de hacerlos salir a la luz pública y que se inician con el volumen titulado Beiträge zur Philosophie. Klostermann:
} 
se opera a su vez la doble identificación de la metafísica con el devenir histórico de Occidente y con el nihilismo diagnosticado por Nietzsche, que desembocará en la temática de su consumación técnica y de su ambivalente superación. Es en atención a este conjunto de cuestiones, que sólo alcanzan a delinearse con nitidez en su obra a raíz del distanciamiento de su anterior compromiso con el nacionalsocialismo, por lo que cabe preguntarse si la comprensión ontológica de la modernidad que Heidegger adquiere a partir de la segunda mitad de los años treinta, y que piensa como corolario de la pérdida de la experiencia griega del ser, resulta solidaria de ciertas nociones políticas de naturaleza intrínsecamente moderna que, pese a no haber sido objeto de examen explícito en sus textos, se dejarían deducir coherente y consistentemente de esa moderna manifestación de las cosas descrita en ellos.

Sin excluir otras vías practicables de abordaje, este trabajo partirá de la hipótesis de que una respuesta plausible a esta problemática se esboza en aquellos lugares en los que la mirada heideggeriana se proyecta sobre el fenómeno griego de la pólis. El primero de ellos que merece reseñarse se localiza en el curso de 1935 Einführung in die Metaphysik, no exento de polémica por el pronunciamiento que en él se efectúa sobre «la verdad interna y la grandeza» del nacionalsocialismo ${ }^{6}$. El tema de la pólis no volverá a aflorar hasta 1942, año en el que se estudia en dos cursos consecutivos: si el primero se centra en la interpretación del himno de Hölderlin Der Ister, el segundo explora la percepción griega de la verdad como alétheia y analiza en función de ella el valor ontológico del mýthos o decir poético griego ${ }^{7}$. La novedad de esta elaboración más tardía se encuentra en la tajante separación que Heidegger establece entre la pólis griega y el Estado moderno, así como en las indicaciones que aporta para entender el sentido específicamente moderno que asigna al concepto de "lo político". Sin embargo, la caracterización del fenómeno pólis coincide en los tres textos en sus rasgos principales y su contemplación conjunta permite ofrecer una exposición unitaria del mismo en la que resaltan varios aspectos. De entrada, hay que subrayar que la exégesis heideggeriana se asienta en todo caso -y aun cuando el curso de 1935 no estará libre de ciertas incongruencias- sobre la negativa a aceptar la traducción de la palabra pólis por los conceptos habituales de Estado o ciudadEstado. Este rechazo se hallará ligado a la inserción de la existencia y configuración de la pólis en el horizonte del surgimiento de la cuestión del ser que para Heidegger explica la realidad griega. En relación con ambos aspectos, su argumentación se focaliza sobre la tesis de que el nacimiento y la construcción de la pólis contienen,

Frankfurt, 1994.

${ }^{6}$ M. Heidegger. Einführung in die Metaphysik. Tübingen: Niemeyer, 1998, p. 152 (en adelante citado como EM).

${ }^{7}$ Se trata de los cursos impartidos, respectivamente, en el semestre de verano de 1942 y en el semestre de invierno de 1942/43, publicados bajo los títulos Hölderlins Hymne "Der Ister". Frankfurt: Klostermann, 1993 (en adelante citado como HHI) y Parmenides. Frankfurt: Klostermann, 1992 (en adelante citado como PA). 
no de manera contingente o accidental sino necesaria, el germen de su propia desaparición. Ello justifica en parte que la interpretación heideggeriana de la pólis evite los textos cardinales de la filosofía griega e ignore fuentes directamente políticas para acudir al decir poético griego y, más concretamente, a la tragedia de Sófocles "Antígona". Pues Heidegger señalará que justamente la forma del decir poético que se realiza en la tragedia tendría por finalidad narrar el declive del mundo griego y, con él, la fatalidad o la ruina (Verderb) que se esconde en la propia estructura de la pólis ${ }^{9}$.

Como habrá de verse, en esa misma desaparición de la pólis Heidegger sitúa el origen de aquello que en la modernidad llegará a constituir "lo político". De ahí que afirme que la pólis «no se deja determinar "políticamente"» porque «la pólis, y precisamente ella, no es un concepto "político"»", para a la vez hacer valer que la naturaleza misma de lo político únicamente puede ser aprehendida a partir de la pólis y de su significación en el mundo griego.

\section{De Grecia y la pólis: dominando el sitio, perder el sitio}

Una clave ineludible del pensamiento heideggeriano reside en la idea de que Grecia se define como tal por el intento de poner de relieve aquello en lo que consiste el ser o aparecer de las cosas en su unidad e irreductible diferencia con respecto a las cosas o entes que son o aparecen. A lo largo de su trayectoria Heidegger insiste en que ese propósito se produce en primera instancia en el mýthos o decir poético ${ }^{11}$ y algo más tardíamente en el tipo de discurso que acabará recibiendo el rótulo de filosofía, cuya especificidad frente al primero radica en su alusión al ser a través de palabras como lógos, alétheia o díke. De acuerdo con esta perspectiva, en el contexto de la tematización de la pólis de 1935, y al hilo de su peculiar lectura de la tragedia "Antígona", esta problemática se expone en términos de la confrontación entre ciertas formas de la téchne -el obrar humano-y la dike, aquí entendida en su equivalencia al ser como el ajuste (Fug), ensamblaje o articulación que posibilita la presencia del ente en su conjunto. Sólo por causa de esa confrontación, recalca

\footnotetext{
${ }^{8}$ En apariencia resulta distinto el curso de 1942/43, dado que en él esta cuestión se presenta a propósito de la Politeia platónica. Sin embargo, su tematización no se dirige al cuerpo del diálogo de Platón, sino al mýthos que se introduce al final de su libro X, término que en el desarrollo de este curso se verá identificado con el decir poético. Por ello, también allí la reflexión sobre la pólis queda expresamente remitida a la tragedia de Sófocles y dominada en su significado por lo planteado en ella.

${ }^{9}$ Cfr. PA, pp. 134 y 168 y EM, pp. 123-24.

${ }^{10}$ HHI, p. 99.

${ }^{11}$ Para la cuestión del valor ontológico que Heidegger atribuye al decir poético griego, puesto que en él se pondría al descubierto el ser a través de la mención de los dioses que se ocultan tras la presencia de las cosas, cfr. P. Martínez Matías, «Entre dioses y hombres: para una interpretación del problema de lo divino y lo sagrado en el pensamiento de Martin Heidegger». Anales del Seminario de Historia de la Filosofía, vol. 31, núm. 1, 2014, pp. 160-165.
} 
Heidegger, el hombre se descubre para Sófocles como tò deinótaton, esto es, como el más inhóspito (das Unheimlichste) de todos los entes, ya que en ella se arranca de la ordinaria familiaridad de las cosas que le son presentes en dirección a su ser o venir-a-presencia ${ }^{12}$. Pero aquellos modos de la téchne por los que acontece la osadía o insolencia (tólma) de querer sacar a la luz no lo que sea ésta o aquella cosa, sino el ser o haber de toda cosa en general, no se limitan en este curso al decir poético -al que se une, por extensión, la esfera de la obra de arte- y al decir pensante, sino que incluyen asimismo la construcción de la pólis ${ }^{13}$. En su emergencia y configuración esencial, la forma de comunidad que representa la pólis quedaría así integrada para Heidegger dentro del proyecto griego de hacer patente el ser llevado igualmente a cabo por poetas y pensadores.

A esta singularidad de la pólis obedece su descripción como el «sitio (Stätte) de la estancia histórica del hombre en medio del ente», es decir, como el espacio abierto «en el cual y a partir del cual y para el cual sucede la historia» $»^{14}$. Pues no es el sentido trivial del concepto de "historia" el que rige en tales afirmaciones, sino aquel que, a lo largo del período que abarca el análisis heideggeriano del fenómeno pólis, se plasma en el denominado "pensar de la historia del ser" (seinsgeschichtliches Denken): en la pólis se ubica el sitio de aquella historia que se inicia con el irrumpir de la interrogación por el ser y que Heidegger acabará por solapar con la metafísica. Para legitimar esta visión apela a la raíz común del término pólis y el verbo pélein, que en los textos de Homero y Hesíodo aún juega el papel de cópula y figura, por tanto, como sinónimo de eínai o ser: en la medida en que el pélein remite al siempre idéntico venir-a-presencia que subyace al movimiento y el cambio del llegar-a-ser y desvanecerse de cada cosa concreta, la pólis constituye el pólos, esto es, el centro (Mitte), eje o espacio de abertura en torno al cual gira toda cosa por tratarse de aquel enclave que «deja aparecer al ente en su ser en la totalidad de su condición $\rangle^{15}$. En consonancia con ello, Heidegger no dudará en inscribir la esencia de la pólis en la alétheia o desocultamiento ${ }^{16}$-como se ha comentado, una de las palabras que se utilizan en los textos del pensar griego en referencia al ser-para caracterizarla como el «sitio del desocultamiento del

\footnotetext{
${ }^{12}$ Cfr. EM, p. 114 y ss.

${ }^{13}$ Cfr. EM, p. 146 y HHI, p. 169. Disentimos en este punto de M. de Beistegui, quien en su interpretación del curso de 1935 no repara en que sólo por los modos mencionados de la téchne -y no por cualquier forma trivial del obrar humano- tiene lugar la confrontación entre ésta y la dike (cfr. Heidegger y lo político, op. cit., p. 189 y ss.). A su lectura debe objetarse que Heidegger distingue claramente entre el común obrar con las cosas y este obrar que pretende poner de manifiesto el ser al subrayar que en la tragedia de Sófocles «el coro dice que este modo de ser no es el cotidiano» (EM, p. 126) en referencia a aquellas formas del actuar que permiten calificar al hombre de tò deinótaton.

${ }^{14}$ EM, p. 117.

${ }^{15}$ PA, p. 133.

${ }^{16}$ Cfr. PA, p. 132 y HHI, p. 106.
} 
ente en total $\rangle^{17}$. Pero si bien estas consideraciones aspiran a enfatizar la vinculación de la pólis a la cuestión ontológica, su significado resulta ciertamente oscuro, dado que Heidegger en ningún momento se detiene a explicar de qué manera su construcción vendría a escenificar el intento típicamente griego de hacer relevante el ser que en ellas se destaca.

Una posible respuesta a esta pregunta se propone, a nuestro juicio, allí donde Heidegger declara que el desocultamiento o manifestación de las cosas que se cumple en la pólis supone un original "reunirse" (sich sammeln) en su "unidad" (Einheit) de la totalidad del ente. Así, la pólis encarnaría el sitio «en el que todo ente y todo conducirse con el ente se reúne» ${ }^{18}$, al tiempo que el fundamento de la unidad que conlleva esa reunión ${ }^{19}$. El sentido que puedan cobrar los conceptos de "reunión" y "unidad" en lo concerniente a la pólis se indica en el curso de 1935 a partir de una dilucidación del significado del lógos en diversos fragmentos de Heráclito. Por un lado, la mención del ser que Heidegger detecta en el lógos heracliteano suscita su interpretación, en línea con el reunirse del ente que acaece en la pólis, como la "reunión originaria" (ursprüngliche Sammlung) ${ }^{20}$. Pero, también siguiendo a Heráclito, en estos pasajes se plantea que si el nómos es la ley (die Satzung) en tanto ensamblaje o articulación (Gefüge) interna de la pólis, ese nómos que vertebra la pólis debe ser concebido en su dependencia con respecto al lógos como la «unidad originariamente unificante de lo que tiende a separarse» ${ }^{21}$. Puesto que la relación de la conformación de la pólis con la cuestión del ser parece establecerse entonces a través del nómos en la señalada supeditación de su sentido al del lógos, la comprensión de esta problemática exigirá una clarificación de su definición que habrá de pasar por estudiar previamente la asimilación heideggeriana del lógos al ser. Ello requerirá de un breve examen del modo en que en Grecia se tiene experiencia de la presencia del ente que servirá para legitimar la atribución a la pólis de la noción de "comunidad" en un aspecto de la misma de particular interés para el trazado de este trabajo.

El que una palabra como lógos pueda haber sido utilizada en los textos de la filosofía griega para nombrar el ser o aparecer de las cosas -circunstancia que no sólo comparte con términos como alétheia o díke, sino también con phýsis o moi$r a$ - obedece a su procedencia del verbo légein. Aun cuando el légein se refiere comúnmente al "decir" -y correlativamente, el lógos al habla- éste no sería para Heidegger su significado primario. Antes bien, el légein apunta de entrada a un reunir o recoger que es a un tiempo discernimiento y selección, esto es, a un juntar que en sí mismo distingue y separa ${ }^{22}$. En su ulterior identificación con el ámbito

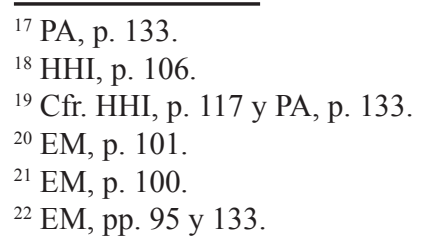


del "decir", ese reunir alude al juntar-separar que acontece en el "decir de algo como algo" contenido en toda oración y que siempre trae consigo el que ese algo quede determinado como algo: en ambas expresiones el "como" (als) configura el elemento articulador que, a la vez que junta a la cosa con las determinaciones que le son propias, implica discernimiento por separarla de aquellas que no le pertenecen. Pero Heidegger mostrará el carácter secundario de tal restricción del légein a la esfera del lenguaje para sostener que con él se designa en primera instancia el poner en una articulación en el que consiste, en general, el aparecer de las cosas y en el que también se produce invariablemente el juntar-separar por el que cada cosa comparece como aquella que es. Tal poner en una articulación tendría lugar en todo habérselas o tratar con las cosas del ser humano -y no sólo en el habla-, pues éstas se manifiestan como aquello que son en el conducirse o tratar con-así, la puerta como puerta al cruzar su umbral-, en el trivial manejarlas y servirse de ellas que atraviesa la totalidad de su existencia ${ }^{23}$.

Debe subrayarse aquí que ese légein que se realiza a cada paso del existir del hombre no entraña en modo alguno un manejarse arbitrario con las cosas que permitiera usarlas con uno u otro fin indistinto. Por el contrario, la determinación del aparecer que sucede en el légein denota un reconocimiento o dejar-ser a la cosa que presupone su estar ya previamente dotada de un modo de ser propio, de una naturaleza o constitución interna a la cual se pliega el habérselas con ella del ser humano. Al igual que ocurre en el poiein o la téchne griegas, no hay en el dejar-ser del légein imposición ni comportamiento caprichoso, sino descubrimiento y asunción de un venir-a-presencia ${ }^{24}$ que, a tenor de la equivalencia en Grecia entre el ser y el límite, coincide con el reconocimiento de los límites por los que cada cosa emerge en su figura específica. Estos no podrán representar entonces límites arbitrarios que se añadan a la cosa desde fuera según la voluntad humana, sino límites por los que cada cosa se instaura en su peculiar presencia distinguiéndose así de cualquier otra ${ }^{25}$. A todo ello cabe agregar que, conforme a la concepción griega de la alétheia -el arrancarse al encubrimiento que, sin embargo, jamás lo supera-, el reconocimiento o dejar-ser que se opera en el légein involucra la percepción de que la presencia de cada cosa envuelve a un tiempo su ocultación: esa misma presencia se constituye sobre el sustraerse o haber quedado atrás de cierto fondo de abertura que sólo alcanza a exhibirse en su propio cierre y reserva y sin cuyo encubrimiento no se daría presencia alguna. A causa de ese intrínseco ensamblaje entre comparecencia y ocultación -ensamblaje que da cuenta del pliegue o doblez por el cual "ser" significa tanto el ser o presencia de esta y aquella cosa como el trasfondo oculto que anida en dicha

\footnotetext{
${ }^{23}$ Cfr. M. Heidegger. Heraklit. Frankfurt: Klostermann, 1994, p. 368 y ss.

${ }^{24}$ Cfr. EM, p. 133.

${ }^{25}$ Cfr. EM, p. 46 y PA, p. 121.
} 
presencia $^{26}$, Grecia habita en la experiencia de que cada cosa, al permanecer en última instancia inaprehensible e inexplicable, es en sí misma consistente o "bella": la opacidad e impenetrabilidad que en ella asume el dejar-ser del légein rehúsa todo intento de reducirla o igualarla a nada diferente de ella misma a no ser a costa de su destrucción.

Este sentido del légein justifica que el término lógos, entendido no ya como el lógos de esta o aquella cosa sino como el lógos sin más, remita en los textos de Heráclito al venir-a-presencia de las cosas en general en su correspondencia con el ser: en el lógos se expresa la "reunión" (Versammlung) o articulación que prevalece en la presencia de cada cosa y la lleva a aparecer como aquella que es en su distinción frente a otras. Dado que el juntar-separar del légein es el mismo para todas -y en su dejar-aparecer siempre ya homologéin o reflejo del $\operatorname{lógoS}^{27}$, esa "reunión" forja, por un lado, la "unidad" de la totalidad del ente. Sin embargo, se trata a la vez de aquella unidad en la que las cosas adquieren su separación y diferenciación porque sólo gracias a ella puede cada una mostrarse en su naturaleza y consistencia propias. En atención a esta idea, Heidegger hace notar que el lógos, igual al pólemos o conflicto por el que cada cosa se afirma en su confrontación frente a lo que no es, sería aquello que asigna a cada una «la ubicación, la posición y el orden de prioridad dentro de la presencia ${ }^{28}$. De ahí que la armonía que trasluce la reunión diferenciadora del lógos se oponga a toda suerte de nivelación, equiparación o anulación de la singular posición que las cosas ocupan o de la especial forma de ser que individualmente les compete $^{29}$ : la reunión originaria del lógos nombra asimismo la abertura o trasfondo oculto que, hurtándose en la presencia de cada cosa, genera su impenetrabilidad e irreductible consistencia y por eso escapa según Heráclito a la mirada cotidiana del hombre corriente.

Es en este punto donde debe recordarse la definición heidegeriana del nómos como articulación que, manteniendo unido lo que tiende a separarse, funda la unidad de la pólis. Pues en razón de ella y de lo que acaba de exponerse cabe plantear que, así como la particularidad de poetas y pensadores en Grecia reside en su pretensión de sacar a la luz el lógos, aquello que incluiría a la pólis en ese mismo proyecto estriba en el hecho de que su construcción se orienta por el propósito de reconocer y hacer tema de su propio ser o ser-comunidad a través de la puesta de manifiesto del nómos antes oculto que la vertebra internamente. Esta aplicación a la pólis de la noción de comunidad puede derivarse parcialmente del modo griego de presencia del ente ya descrito: que las cosas posean una naturaleza o consistencia propias a la cual debe plegarse el

\footnotetext{
${ }^{26}$ Sobre esta cuestión, cfr. P. Martínez Matías. «Entre dioses y hombres: para una interpretación del problema de lo divino y lo sagrado en el pensamiento de Martin Heidegger», op. cit. p. 166 y ss.

${ }^{27}$ Cfr. M. Heidegger. «Logos». Vorträge und Aufsätze. Stuttgart: Neske, 2000, p. 207.

${ }^{28}$ Cfr. EM, p. 47.

${ }^{29}$ Cfr. EM, p. 102.
} 
actuar del ser humano legitima la determinación de fines $u$ objetivos estrictamente comunes que se ajusten a esa misma naturaleza. Por ello, la singularidad de la pólis frente a las comunidades bárbaras o precedentes radicará -entre otros aspectos- en su estructuración en torno a sus reiterados intentos de hacer patente y fijar a través de la ley escrita, que es espejo del ${\operatorname{ló} g o s^{30}}^{30}$, «aquello que está permitido y no está permitido -aquello que es ajustado y lo desajustado, aquello que es conveniente y lo no conveniente $\rangle^{31}$ en virtud de esa forma de ser que las cosas en sí mismas ostentan. El que el contenido del nómos no fuera en un principio idéntico para todos los habitantes de la pólis indica que con tal fijación se procede a su vez al reconocimiento del orden interno previamente dado que en ella impera según las relaciones y vínculos que sus respectivas diferencias -sus diversas tribus de origen, sus linajes y fratrías en que se agrupan $^{32}$ marcan entre ellos. Así, según apunta Heidegger de acuerdo con su análisis del lógos, la ley haría expresa la articulación originariamente latente que, sobre la base de tales divergencias, también asigna a cada miembro de la pólis su posición y función propias ${ }^{33}$. Pero en la medida en que con él -de nuevo de manera similar al lógos- viene a ponerse de relieve un "lo mismo" para todos, el nómos desvela la unidad capaz de reunir y mantener unidos en su separación a sus habitantes: por más que las prescripciones del nómos difieran de entrada para los distintos miembros de la pólis, todos ellos se hallarán igualmente sometidos a la ley escrita, y esa igualdad implicará -por poner a la vista quiénes pertenecen a ella y quiénes no- el reconocimiento de los límites que configuran la entidad unitaria de la pólis $^{34}$.

Por obra de esos repetidos intentos de fijación del nómos que llevarán a su continuada revisión podrá decir Heidegger que la pólis es «el ámbito que fue siempre de nuevo cuestionable y permaneció cuestionable, e hizo necesarias y urgentes decisiones cuya verdad trasladó a los griegos a lo falto de suelo» ${ }^{35}$ : si se acepta que la dominación del sitio que Heidegger lee en el término hýpsípolis del coro de "Antígona" se materializa en esa explicitación del nómos, su reflexión no dejará de insistir en que tal dominación, según la confluencia de lo hýpsípolis con lo ápolis atestiguada por Sófocles, habrá de abocar necesariamente a la ruina o el desastre que supone la pérdida de ese mismo sitio $^{36}$. Una vez más la comprensión de este rasgo atribuido a la pólis pende de la perspectiva más general del surgimiento de la cuestión ontológica

\footnotetext{
${ }^{30}$ Sobre el hecho de que el nómos reflejaría el lógos o el ser en el ámbito de la pólis, cfr. G. Fried. Heidegger's Polemos. From Being to Politics. New Haven \& London: Yale University Press, 2000, p. 147.

${ }^{31}$ HHI, p. 101.

${ }^{32}$ Cfr. A. Míguez. «Comunidad y desarraigo: aproximación al fenómeno pólis». Isegoría, núm. 40, 2009, p. 207.

${ }^{33}$ Cfr. HHI, p. 100.

${ }^{34}$ Cfr. F. Martínez Marzoa. La cosa y el relato. Madrid: Abada, 2009, p. 21 y ss.

${ }^{35}$ HHI, p. 99.

${ }^{36}$ Cfr. EM, p. 124, HHI, pp. 107 y 110, y PA, pp. 133-35.
} 
en Grecia. Heidegger considera que el intento de tornar relevante el ser o -lo que es equivalente en este caso- la dimensión no objetivable ni aprehensible que encierra la aparición de cada cosa y que sólo comparece en su sustraerse, acabará por anular tal fondo de abertura encubierto para transformar esa presencia antes huidiza y opaca en mera presencia sin fondo ni ocultación. Con semejante anulación no sólo se produce la conversión del ser en ente y, más concretamente, en lo verdaderamente ente que deviene fundamento de la entidad de todo lo demás, sino que se condena a la presencia antes consistente e impenetrable de las cosas a la inconsistencia de lo que propiamente no $\mathrm{es}^{37}$. El aplanamiento o anulación de la diferencia entre el ente y su ser suscitado por su tematización conlleva, en este sentido, la igualación y equiparación, el aplanamiento y disolución de la belleza de las cosas y de su esencial diferencia.

El que tal vuelco en la experiencia griega del ser tenga también por efecto el eclipsarse de la percepción en las cosas de una naturaleza propia a la que atenerse habrá de terminar por impedir, como veremos en el siguiente apartado, la espontánea disposición de fines comunes a partir de aquélla que se ha asociado a la pólis. Sin embargo, la extrapolación de este giro al terreno más específico de su organización y articulación internas conduce a señalar que el repetido cuestionamiento del nómos que en ella tiene lugar y que provoca su progresiva fijación representaría asimismo el germen de la destrucción que, para Heidegger, se alberga en esta comunidad singular. Esto podría explicarse por la circunstancia de que el mencionado establecimiento de una ley a la que todos sus miembros se encuentran idénticamente sujetos $-\mathrm{y}$ aun cuando ésta, como se ha resaltado, no prescriba originalmente relaciones idénticas para todos- no deja de comportar la introducción de un principio de igualación y uniformización paralelo al que afecta al ente: al dar pie en sus sucesivas revisiones a leyes cada vez más igualitarias y volver así problemático el discernimiento sobre quién y quién no pertenece a la comunidad, esta situación acabará por desdibujar los límites esenciales de la pólis ${ }^{38}$ y con ello su propia entidad, solidaria en Grecia de esos mismos límites. De esta manera, la forma de comunidad que, según la visión heideggeriana, se construye en el intento de reconocer su propio estatuto o ser a través de la ley desembocaría indefectiblemente en su propia extinción.

\section{Estado moderno y poder}

A partir de su incipiente diálogo con la poesía de Hölderlin, Heidegger comienza ya a finales de 1934 a formular la tesis de que la modernidad no es sino el resultado de la pérdida irreparable de Grecia y, por tanto, una época histórica cuya radical diferencia frente a ella debe ser asumida con el fin de descartar todo vano anhelo de

\footnotetext{
${ }^{37}$ Cfr. EM, pp. 137-141.

${ }^{38}$ Cfr. F. Martínez Marzoa. La cosa y el relato, op. cit., p 11 y ss.
} 
imitación o regreso al mundo griego ${ }^{39}$. Pero a pesar de que todos aquellos momentos en los que Heidegger se ocupa del fenómeno de la pólis parten del rechazo a traducir este concepto por cualquier término de raigambre moderna, ya se anticipó que su tematización en 1935 no está exenta de incongruencias que le llevarán a mencionar la existencia en Grecia de "hombres de Estado" (Staatsmänner) en referencia a los gobernantes ${ }^{40}$. Ello probaría la inmadurez en este punto de esa interpretación de la modernidad que no habrá de perfilarse con precisión hasta $1938^{41}$, al tiempo que la falta de una reflexión suficiente sobre sus repercusiones en el plano de lo político. Tal confusión en lo que concierne a la frontera que separa lo griego y lo moderno ya no será posible en sus posteriores disquisiciones sobre la pólis: en ellas Heidegger introduce una nítida distinción entre ésta y el Estado moderno en razón de la cual, como se dijo, el concepto mismo de lo "político" queda restringido a la modernidad y se presenta como una "consecuencia esencial" de la desaparición de la pólis ${ }^{42}$.

Por lo pronto cabe destacar la relación que Heidegger advierte entre el Estado moderno y el concepto de poder (Macht), así como su afirmación de que, en contraposición al primero, la "esencia del poder" sería ajena, extraña a la pólis. Qué deba entenderse bajo la noción de poder en este contexto se remite a la consideración de que su esencia se fundaría en cierto presupuesto de índole metafísica, a saber, el presupuesto «de que la esencia de la verdad se ha transformado en certeza, es decir, en la certeza de sí (Selbstgewißheit) de la esencia humana que se pone a sí misma, y en el hecho de que ésta reposa en la subjetividad de la conciencia» ${ }^{43}$. Frente a la condición intrínsecamente cuestionable de la pólis en su voluntad de determinar su propio estatuto por medio de la explicitación del nómos, sobre esa verdad moderna convertida en certeza descansará el carácter necesaria e incondicionalmente no cuestionable que Heidegger concede a "lo político" en su anclaje en la conciencia moderna. Pero la inteligibilidad de esta idea de "lo político" en su exclusión del mundo griego pasa por aclarar que, según se desprende tanto de los escritos privados de Heidegger como de las lecciones sobre Nietzsche iniciadas en esta misma etapa, la noción de "poder" a la que aquí se apela posee un sentido en primera instancia ontológico y sólo derivadamente político. Veámoslo más detenidamente.

La interrogación griega por el ser que ocasiona la disolución de la pólis genera igualmente una transformación de la comprensión griega de la verdad como alétheia -el desocultamiento que permanece entregado a la ocultación-que culmina en su moderna asimilación a la certeza. En su elaboración paradigmática en la filosofía

\footnotetext{
${ }^{39}$ En el primero de los cursos sobre la poesía de Hölderlin que Heidegger imparte en el semestre de invierno de 1934/35 y que lleva por título Hölderlin Hymnen "Germanien" und "Der Rhein". Klostermann: Frankfurt, 1999. A este respecto, cfr., por ejemplo, p. 205.

${ }^{40}$ Cfr. EM, pp. 47 y 117.

${ }^{41}$ En la conferencia «Die Zeit des Weltbildes». Holzwege. Klostermann: Frankfurt, 2003.

${ }^{42}$ Cfr. PA, p. 142.

${ }^{43}$ PA, p. 135; cfr. también HHI, p. 117.
} 
de Descartes, este nuevo concepto de verdad tiene su origen en la búsqueda de un fundamento absoluto e inconmovible para el conocimiento: situado éste en la res cogitans, lo verdadero se traslada al espacio de la conciencia y sus representaciones, en el que únicamente será admitido como ente aquello que satisfaga las exigencias de certeza e indubitabilidad prescritas por el sujeto pensante. La totalidad de las cosas deviene entonces mero "objeto" del representar humano, que dicta y pone desde sí, para el aseguramiento de su saber, los criterios de validez de su presencia. Según Heidegger, tales criterios se resumen en la calculabilidad capaz de garantizar la certeza del sujeto sobre el contenido de sus representaciones. Por este motivo, la normatividad finalmente asignada a los principios de la ciencia físico-matemática y la uniformización que en función de ellos se ejerce sobre el ámbito de la naturaleza acabará por solapar lo ente como tal con la esfera de lo estrictamente medible y computable ${ }^{44}$. No obstante, la fuente última de esa búsqueda de seguridad y certeza que alienta en el hombre moderno habrá de emplazarse en su pretensión de dominar, conquistar y poner a su disposición la totalidad de las $\operatorname{cosas}^{45}$. De ahí que, a juicio de Heidegger, la noción cartesiana de verdad como certeza se asiente subrepticiamente sobre la voluntad de poder que Nietzsche descubre en el despliegue de la filosofía occidental y que aspira a la ordenación y dominio incondicionales del ente ${ }^{46}$.

Desde este enfoque, Heidegger defiende que a la concepción moderna de la verdad le correspondería una forma singular de manifestación de las cosas de la que depende en último término la exigencia de su calculabilidad: aquella que identifica con la esencia del poder y que designa en esta etapa con la noción de "maquinación" (Machenschaft) ${ }^{47}$, concebida posteriormente como la esencia de la técnica. En virtud de la construcción de este concepto a partir del verbo "hacer" (machen), la comparecencia del ente que nombra la maquinación y que revela el modo en que las cosas son en la modernidad se cifra en su factibilidad o producibilidad, pues, como Heidegger anota, para el hombre moderno «sólo el ente que se puede hacer (machbar) lo es todo» ${ }^{48}$. Con la equivalencia instituida entre la entidad de las cosas y su producibilidad a través de la planificación y el cálculo requeridos por ésta, el ente en su conjunto se exhibe como lo enteramente disponible para el hacer humano, es decir, como aquello con lo que de antemano cabe contar de manera incondicional en vistas a cualquier género de realización o producción. La maquinación constituirá por ello la esencia del poder en una significación puramente ontológica de este concepto: bajo su luz, la totalidad del ente se restringe a lo que puede ser hecho y producido o,

\footnotetext{
${ }^{44}$ Cfr. M. Heidegger. Nietzsche II. Frankfurt: Klostermann, 1997, pp. 164-65 (en adelante, citado como NII). Cfr. también M. Heidegger. Die Frage nach dem Ding. Tübingen: Niemeyer, 1987, pp. 70-72.

${ }^{45}$ Cfr. NII, p. 169.

${ }^{46}$ Cfr. NII, pp. 181-82

${ }^{47}$ Cfr. M. Heidegger. Die Geschichte des Seyns. Frankfurt: Klostermann, 1998, p. 44 (en adelante, citado como DGS), así como NII, p. 21 y ss.

${ }^{48}$ DGS, p. 201; cfr. también p. 46 y ss.
} 
lo que es lo mismo, a lo susceptible de sometimiento al poder en tanto imposición arbitraria de cualquier proceso de manipulación y transformación que se desee sin reconocimiento de límite alguno interno a la naturaleza de las cosas que coarte ese hacer del sujeto.

Se evidencia así cómo el moderno devenir de la verdad en certeza supone un giro decisivo con respecto a la experiencia griega del ser: si la aparición del ente en Grecia quedaba indisolublemente entrelazada con el hurtarse del fondo de abertura que la hace posible, la liquidación de esa dimensión oculta a raíz de su tematización dará lugar a aquella forma de presencia del ente caracterizada por la inexistencia de todo resquicio de oscuridad que se oponga a la presentación exhaustiva del mismo reclamada por su producibilidad. La consecuencia de esa pérdida de la antigua opacidad y consistencia de las cosas se plasmará en el carácter ilimitado del poder de la maquinación ${ }^{49}$ : frente al dejar-ser que en Grecia involucra la relación con las cosas como reconocimiento de los límites consustanciales a su específica naturaleza, con la maquinación la subjetividad moderna «no sólo queda liberada de todo límite, sino que ella misma dispone ahora de todo poner y quitar límites $\aleph^{50}$, que se convierten en límites advenidos sobre la cosa según la voluntad del sujeto. De igual manera, el requisito de transparencia del ente para la representación demanda la ausencia en éste de todo elemento vinculante al cual deba sujetarse el hacer humano, para desplazar a ese mismo hacer y al ejercicio de su poder la decisión sobre los vínculos a establecer con é $\left.\right|^{51}$. A este respecto, Heidegger comenta que la manifestación del ente como poder que es inherente a su producibilidad «es la contra-esencia (Unwesen) de la esencia inicial (...) del ser como phýsis ${ }^{22}$ : en contraposición a la ocultación que envuelve el venir-a-presencia referido por la phýsis griega, y de la cual surge la necesidad de plegarse a un mundo de cosas cuya irreductible consistencia proviene de la percepción de su íntima impenetrabilidad, la maquinación moderna, como reverso y reflejo de su desaparición, no puede sino afirmar la inconsistencia del ente y negar en él toda dimensión oculta que rechace su plena producibilidad, así como cualquier condición a su ser-factible que sobrepase las impuestas por el actuar humano.

El enraizamiento del poder que Heidegger asocia al Estado moderno en este poder de signo ontológico inscrito en la maquinación justifica que tanto la definición de aquel como la de lo político se remitan a la interpretación de la verdad como certeza que sustenta esta forma de comparecencia del ente. Heidegger plantea que la singularidad del Estado y de la emergencia del fenómeno típicamente moderno de lo político estribaría en la proyección del paradigma de la certeza sobre la esfera del actuar humano, aquí asimilada al campo de la historia, en el que la exigencia de

\footnotetext{
${ }^{49}$ Cfr. DGS, p. 202.

${ }^{50}$ NII, p. 199; cfr. también p. 171 y ss.

${ }^{51}$ Cfr. NII, p. 148.

${ }^{52}$ DGS, p. 62
} 
calculabilidad que se sigue de este concepto de verdad se traduce en la voluntad de regular la vida humana conforme a la misma calculada planificación que rige para el resto de cosas. En este sentido, Heidegger señala que «lo político es la certeza fundamental técnico-historiográfica de todo actuar ${ }^{53}$, es decir, el resultado de la imposición de aquellos criterios que garantizan la seguridad perseguida por la conciencia moderna en el conocimiento del ente sobre el marco de la acción y la decisión. Pero que lo político se iguale asimismo a «la realización (Vollzug) de la historia ${ }^{54}$ indica una suerte de extensión del poder de la maquinación sobre el comportamiento humano: al nacimiento de lo político subyacería la premisa de que también la historia es algo que se puede "hacer" por medio de la dirección calculada y planificada de la conducta. En consonancia con ello, la descripción heideggeriana del Estado como «la forma fundamental moderna en la que la conciencia específicamente moderna, en cuanto conciencia que se pone a sí misma, ordena todo ente» ${ }^{55}$ sugiere, y así lo ratifican sus escritos privados ${ }^{56}$, que la pretensión de someter al cálculo las acciones que determinan el curso de la historia se hallaría al servicio de la producción incondicionada del ente que impera por obra de la maquinación.

A causa de ese prevalecer de la certeza en la constitución del Estado moderno, Heidegger observa un esencial ensamblaje entre la ausencia de cuestionamiento de lo político y la "totalidad" (Totalität) que acusa en él. Sin embargo, el recíproco pertenecerse de ambos aspectos, escribe Heidegger, «no reposa, como creen algunos espíritus ingenuos, sobre la arbitrariedad accidental de los dictadores, sino que descansa absolutamente sobre la esencia metafísica de la realidad moderna $\rangle^{57}$. Nada parece haber de inocente en esta mención a los "dictadores" ante un auditorio en cuyos oídos, al escuchar en 1942 la palabra "totalidad", no podía dejar de resonar la noción del "Estado total" ya introducida en el debate político a principios de los años treinta por Carl Schmitt y Ernst Forsthoff y utilizada por el propio Hitler y otros juristas como Erik Wolf para aludir al Estado nacionalsocialista ${ }^{58}$. Con ella, y tal vez en un sentido análogo a la constatación schmittiana de la existencia de un Estado total en el siglo XX en referencia a su injerencia en todos los ámbitos de la vida ${ }^{59}$, Heidegger advierte que, lejos de ser un rasgo tan sólo imputable al Estado nacionalsocialista de la Alemania del momento, esa totalidad de lo político apelaría a un carácter inmanente al modo

\footnotetext{
${ }^{53}$ HHI, p. 117.

${ }^{54}$ Íbid.

55 Íbid.

${ }^{56}$ Cfr. DGS, p. 188.

${ }^{57}$ Cfr. PA, p. 118.

${ }^{58}$ Cfr. H. Arendt. Los orígenes del totalitarismo. Madrid: Taurus, 1998, p. 319 y E. Faye. Heidegger. La introducción del nazismo en la filosofía, op. cit., p. 288.

${ }^{59} \mathrm{Cfr}$. a este respecto C. Schmitt. «Weiterentwicklung des totalen Staates in Deutschland», en Positionen und Begriffe im Kampf mit Weimar-Genf-Versailles 1923-1939. Berlin: Dunker \& Humblot, 1994, pp. 211-216.
} 
en que éste aparece en la modernidad en correspondencia con la manifestación del ente como terreno de lo factible y producible. La configuración totalitaria del Estado nacionalsocialista tendría entonces su condición de posibilidad en esa totalidad de lo político que se liga al Estado moderno en razón de la ordenación de la totalidad de las cosas y de la dirección del actuar humano sobre ellas que éste lleva a cabo.

Esta conclusión vendría avalada por el hecho de que, también en el contexto de sus escritos privados, Heidegger estima que otras posiciones políticas diversas al nacionalsocialismo y distintas entre sí, como serían el liberalismo y lo que denomina el "bolchevismo", arraigarían igualmente en la comprensión de la verdad como certeza ${ }^{60}$, de manera que ambas se verían a su vez afectadas por esa totalidad de lo político que se ha derivado de tal comprensión. En línea con esta equiparación y al hilo de una reflexión sobre el poder en su significación ontológica en la que de nuevo aflora el tema de la totalidad de lo político ${ }^{61}$, Heidegger detecta una "mismidad metafísica" en las formas de Estado en principio opuestas que serían los Estados parlamentarios y los Estados autoritarios. Tal mismidad metafísica se cimentará en este caso, entre otros factores, sobre el recurso de ambas posiciones políticas a la proclamación de un "ideal" que Heidegger identifica con «una "idea" de la comunidad humana y su felicidad [que] es puesta como norma para la pacificación y ordenación de lo "real" y con ello de su remodelación» ${ }^{62}$. En función de lo expuesto sobre las diferentes formas de presencia del ente vigentes en Grecia y en la modernidad, debe llamarse la atención en este punto sobre la aparente incongruencia de esta asignación al Estado de la "idea" de una "comunidad": si la experiencia griega de una naturaleza o modo de ser propio en las cosas explica la delimitación de fines comunes que opera en la pólis en respuesta a esa naturaleza interna, la ordenación del ente practicada por el Estado moderno a partir de la maquinación obedecería, por el contrario, a una desvinculación de todo contenido sustancial en las cosas en principio incompatible con la instauración de cualquier clase de comunidad en esta acepción del término. No obstante, la aclaración del sentido de estos pasajes precisa tener en cuenta que lo aquí presentado como un "ideal" se utiliza como sinónimo de lo que en otras ocasiones Heidegger llama "sentido", "fin" o "meta" en su común remisión al "valor". La importancia de esta noción en sus análisis de la modernidad a partir de su confrontación con el pensamiento de Nietzsche proviene de la solidaridad que le atribuye tanto con la moderna factibilidad del ente como con la búsqueda de certeza que la soporta y que fundamenta el carácter total de lo político. Atender a esta relación entre lo político y el valor que, como veremos en el siguiente apartado, Heidegger aprecia en las organizaciones políticas de la modernidad en conexión con su totalidad no sólo permitirá concretar el significado de este concepto. También

\footnotetext{
${ }^{60}$ Cfr. M. Heidegger. Beiträge zur Philosophie, op. cit., pp. 53-54.

${ }^{61}$ Cfr. DGS, p. 182.

${ }^{62}$ DGS, p. 189.
} 
nos llevará finalmente a la pregunta acerca de la forma de Estado que podría ser coherente con la "esencia metafísica de la realidad moderna" explicitada en su obra y con su potencial superación.

\section{Metafísica y nihilismo: la renuncia a los valores}

Ya se mencionó anteriormente que, en los cursos que dedica entre 1936 y 1941 a la filosofía de Nietzsche, Heidegger interpreta la noción de voluntad de poder como expresión del modo de presencia del ente que en sus textos se cifra en la maquinación. $\mathrm{Si}$ en la perspectiva nietzscheana la voluntad de poder se despliega mediante la posición de valores imprescindibles para su conservación y crecimiento - es decir, para el avance incondicionado de su dominio sobre el globo terráqueo-, Heidegger hace notar que los valores no son sino el producto del cálculo que la voluntad de poder proyecta sobre las cosas con el fin de garantizarse ese incremento de sí que persigue su propio aseguramiento. Por este motivo, juzga que en la obra de Nietzsche se efectúa una reducción del ser al valor: las condiciones de posibilidad de la aparición de todo ente equivaldrán en ella a su valer y servir para el acrecentamiento de la voluntad de poder según la medida computable de esa utilidad. Sin embargo, este distanciamiento crítico es en parte fruto de la adhesión de Heidegger a la comprensión nietzscheana de la metafísica como historia oculta de las diferentes posiciones de valor de la voluntad de poder que habrá de salir a la luz con la desvalorización de los valores supremos que marca su final. Por más que el ser humano se imponga en la globalidad de su recorrido como medida del valor de todas las cosas, en sus inicios permanece inconsciente con respecto al origen de esos valores que él mismo sitúa por encima de sí y a los que se somete, según Heidegger, con el secreto objetivo de asegurarse una meta en la $v$ ida $^{63}$. Sólo con el moderno erigirse del hombre en el subiectum que prescribe desde la certeza de su representar los principios de la presencia válida del ente y, con ello, lo necesario y vinculante en lo relativo a su conocimiento del mundo y a su actuar en él, la voluntad de poder comienza a cobrar conciencia de sí y a afirmarse en su pretensión de dominio. Pero el sujeto moderno aún creerá obedecer a instancias -la razón y su ley, la autoridad de la conciencia, el progreso histórico, la felicidad de la mayoría... ${ }^{64}-$ que lo trascienden y siguen teniendo sobre él una función normativa, si bien el gradual descubrimiento de la imposibilidad de conquistar tales metas, ideales o valores, cuya legitimidad procedería de su presunta objetividad, terminará por mostrar que su origen no es otro que la voluntad de poder que se realiza en el ser humano. La consecuente caducidad y pérdida final de su creencia en ellos atestigua el estado de cosas que Nietzsche designa como el nihilismo, noción que a su vez se dejaría aplicar a la totalidad del curso de la metafísica si la posición de valores que conforma

\footnotetext{
${ }^{63}$ Cfr. NII, p. 102 y ss.

${ }^{64}$ Cfr. NII, pp. 145 y 273, así como «Nietzsches Wort “Gott ist tot”». Holzwege, op. cit., p. 220.
} 
su devenir se encuentra de antemano destinada a la posterior desvalorización de los mismos que evidencia su instauración por parte del hombre.

También en lo que concierne a la culminación de la modernidad que articula su propio presente Heidegger acepta el diagnóstico nietzscheano del nihilismo: se trata de la situación en la que, alcanzado el cumplimiento de la nihilidad intrínseca a la metafísica desde su surgimiento, «todas las metas han desaparecido» ${ }^{65}$. Pero, desde su enfoque ontológico, esta descripción del nihilismo se limita a mostrar el primer plano de un acontecimiento de mayor calado, consistente en lo que denomina el "permanecer-fuera" (ausbleiben) o no-aparecer del ser ${ }^{66}$. Con esta fórmula Heidegger apunta en el contexto de sus lecciones sobre Nietzsche a la obliteración del trasfondo de abertura oculto que genera el intento griego de ponerlo de relieve y sobre cuya sustracción o retirada se construye la historia de Occidente en su asimilación a la metafísica. Ese trasfondo aquí equiparado al ser comparece en ella en el paradójico modo de su ausencia a través de la moderna manifestación de las cosas como objetos enteramente producibles para el hacer humano. Por haber conducido a su producción incondicionada, ya exclusivamente guiada por el propósito de la producción por la producción misma, la consumación de esa forma de desocultamiento del ente en el ascendente dominio de la técnica delata el desvanecimiento de toda meta: según se vio, es precisamente la propia constitución de esa presencia moderna como poder lo que impide el reconocimiento de una naturaleza propia en el ente a partir de la cual cupiera fijar reglas de conducta a seguir frente a él o tomar decisiones con respecto a su uso. Heidegger identificará por ello el nihilismo con la época de la "acabada falta de sentido" 6 : bajo la percepción de que su venir-apresencia es obra del ser humano, las cosas se han tornado meros reflejos de su hacer que han dejado de ofrecer fines objetivos a los que atenerse, dado que su objetividad sólo puede provenir de la normatividad del cálculo que las hace susceptibles de plegarse a cualquier fin que se les dicte.

Pero si ese permanecer-fuera del ser representa lo propio del nihilismo, la metafísica involucra asimismo el llamado "dejar-fuera" (auslassen) del permanecer-fuera del ser ${ }^{68}$ : al tiempo que resulta incapaz de hacerse cargo de la sustracción del ser que inicia su desenvolvimiento, la metafísica ejerce inadvertidamente una tenaz desfiguración sobre ella. Por este dejar-fuera, el nihilismo acaece en la impropiedad de sí mismo, pese a que tal condición sería inevitable por emerger de la retirada del ser y de su conversión en lo verdaderamente ente que provoca su tematización en Grecia. Hay que destacar aquí que en la etapa final de la modernidad, en la que la abertura técnica del ente comienza a imperar en todos los ámbitos de la existencia humana, la impropiedad del nihilismo se acredita para Heidegger en el encubrimiento de la falta de metas - esto es, de la des-

\footnotetext{
${ }^{65}$ M. Heidegger. Beiträge zur Philosophie, op. cit., p. 138.

${ }^{66}$ Cfr. NII, p. 353.

${ }^{67}$ Cfr. NII, p. 20 y DGS, p. 201.

${ }^{68}$ Cfr. NII, p. 359 y ss.
} 
valorización de los valores supremos-a través de la reiterada invocación de metas y valores siempre cambiantes que únicamente marcan una dirección a la acción humana como medios o instrumentos resultantes del cálculo para la continuada expansión de la producción incondicionada del ente ${ }^{69}$. Y en tal encubrimiento divisa el signo de una intuición huidiza del nihilismo que invariablemente lo rechaza: como expresa gráficamente, «nadie quiere confesarse a sí mismo la falta de metas» $\rangle^{70} \mathrm{y}$ sólo la igualmente «inconfesada angustia ante la angustia, que experimenta como terror el permanecer-fuera del ser» ${ }^{71}$, suscita la ofuscación que busca refugio en una nueva posición de valores y metas. Pues en ésta se hace patente que nada entrañaría mayor dificultad para el sujeto moderno que asumir la circunstancia de habitar un mundo cuya configuración técnica elude de raíz el establecimiento de criterios de actuación objetivamente vinculantes. De acuerdo con esta idea, la lectura heideggeriana del pensamiento de Nietzsche habrá de inscribirlo -en contra de su propia autoconciencia- en el interior de la metafísica: en su postulado de que la superación del nihilismo pasaría por la formación de un nuevo principio de posición de valores se localizaría el último y más decisivo paso del enmascaramiento de la sustracción del ser vigente en la impropiedad del nihilismo ${ }^{72}$.

Como se declara en sus escritos privados, esa institución de metas y valores pertenecería esencialmente a toda forma de organización política moderna, aun cuando llega a ser especialmente visible en el momento en que el incremento de la voluntad de dominio sobre la totalidad de las cosas impulsa una lucha entre naciones por el poder mundial que, practicada tanto en tiempos de guerra como de paz, se libra mediante la proclamación de metas de contenidos dispares pero indefectiblemente orientadas a encubrir la ausencia de metas consustancial a la voluntad de poder. Poco importa que tales metas residan en la defensa de la moralidad, la libertad o la justicia social, en la protección de los bienes "espirituales" de la humanidad o en la preservación de su "sustancia" “corpórea"’z: desde la perspectiva de esa implantación de valores para el mantenimiento y aumento de un poder cuya esencia metafísica $-\mathrm{y}$, como se ha resaltado, sólo secundariamente políticadesafía de continuo al ser humano a disponer de manera creciente sobre el ente en cuanto tal, regímenes tan distintos como el liberalismo -el "Estado inglés"- o el comunismo se revelarían idénticos ${ }^{74}$. En clara alusión al nacionalsocialismo, Heidegger incluye entre esas metas «la salvación de lo inherente al pueblo» o la «aseguración de su eterno estado "racial" $\gg 75$, al tiempo que identifica la idea de "pueblo" con uno de los valores elevados

\footnotetext{
${ }^{69}$ Cfr. DGS, pp. 76 y 201-2; NII, por ejemplo, p. 28 y «Überwindung der Metaphysik». Vorträge und Aufsätze, op. cit, p. 87.

${ }^{70}$ M. Heidegger. Beiträge zur Philosophie, op. cit., p. 139.

${ }^{71}$ NII, p. 393.

${ }^{72}$ Cfr. NII, p. 338 y ss.

${ }^{73}$ DGS, pp. 76 y $182-83$.

${ }^{74}$ Cfr. DGS, pp. 208-09.

${ }^{75}$ Cfr. DGS, p. 183.
} 
para el encubrimiento del nihilismo ${ }^{76}$. Sin embargo, que Heidegger -como se recordará- observe que formas de Estado tan dispares como la parlamentaria y la autoritaria se erigen sobre la afirmación de un "ideal" de "comunidad" indica que tal afirmación dependería no tanto de la naturaleza de las metas proclamadas en ellos -"el pueblo" en el Estado nacionalsocialista- como de la instauración misma de metas, fines o ideales determinantes de un objetivo común para una colectividad dada. En esa instauración se hallaría, a nuestro entender, no sólo el rasgo definitorio del nihilismo impropio, sino también el principio explicativo del carácter total que Heidegger asigna a lo político en su pretensión de ordenar y planificar "técnicamente" la actuación humana en vistas a la producción incondicionada de todo lo real. En virtud de ese carácter total de lo político, en la consumación de la metafísica los valores regirían plenamente como «criterios de medida impuestos al comportamiento humano» ${ }^{77}$ en el más estricto sentido de la palabra "imposición": su falta de legitimidad sería el necesario corolario de la no reconocida y encubierta desvalorización de los valores supremos; o, lo que es lo mismo, del enmascaramiento de la imposibilidad que se deriva de la maquinación de asentar metas o fines comunes que funden alguna suerte de comunidad política. La consecuencia más destructiva de esa posición de valores que promueve lo político en su ordenación y dirección total de la existencia humana para el incremento ilimitado del dominio técnico sobre la tierra radicará en que, pese a su aparente control sobre cualquier proceso productivo, el hombre del final de la modernidad ha acabado sometido a un régimen de servidumbre por el cual deviene mero "animal de trabajo" $"$, pura materia prima, "material humano" 79 o simple mercancía sujeta a los mecanismos de potencial compra-venta que administran la totalidad del ente ${ }^{80}$ : subyugado en su actuación por la misma lógica calculadora que gobierna el resto de cosas en su factibilidad, en la impropiedad del nihilismo el ser humano aparece como un ente íntegramente empleable a la vez que reemplazable en el terreno de un hacer omnipresente que todo lo gestiona ${ }^{81}$.

Pero si ésta es la amenaza que comporta para el hombre la moderna presencia del ente en el cumplimiento de la metafísica, Heidegger también sostendrá que en su propio despliegue se alberga la posibilidad de su superación ${ }^{82}$. No obstante, ésta no podrá tener lugar ni en el rechazo de la maquinación y su poder ni en la restauración de un pasado ya irrecuperable ${ }^{83}$. Antes bien, Heidegger piensa que la superación de la metafísica y de su nihilidad impropia se emplazaría en un «saber de la maquinación que no la evite a través de ningún encubrimiento, y con ello se encuentre bajo

\footnotetext{
${ }^{76}$ Cfr. M. Heidegger. Beiträge zur Philosophie, op. cit., p. 139.

${ }^{77}$ Cfr. NII, p. 49.

${ }^{78}$ Cfr. M. Heidegger. «Überwindung der Metaphysik». Vorträge und Aufsätze, op. cit., pp. 68-69.

${ }^{79}$ Cfr. NII, p. 387 y DGS, p. 185.

${ }^{80}$ Cfr. M. Heidegger. «Wozu Dichter?». Holzwege, op. cit., p. 292 y ss.

${ }^{81}$ Cfr. DGS, p. 185.

${ }^{82}$ Cfr. M. Heidegger. «Die Frage nach der Technik». Vorträge und Aufsätze, op. cit., p. 30 y ss.

${ }^{83}$ Cfr. DGS, p. 45.
} 
su ineludible dominio y lo resista $\rangle^{84}$. En razón de lo ya expuesto, semejante saber equivaldría a un reconocimiento de la impropiedad del nihilismo que, en cuanto tal, exigiría el descubrimiento de lo que le es propio: cifrado éste en la retirada del ser hasta entonces oculta que origina el desenvolvimiento de la metafísica ${ }^{85}$, tal descubrimiento sería idéntico a la percepción de que la comparecencia del ente como objeto enteramente factible y disponible, lejos de ser algo "hecho" por el ser humano, constituye por el contrario un acontecimiento del que éste en absoluto dispone. Pero en la medida en que el enmascaramiento de la maquinación se produce según Heidegger por medio de la posición de valores y metas destinados a disimular la carencia de sentido reinante en la última etapa de la modernidad, ese saber de la maquinación capaz de eludir todo encubrimiento no podrá consistir más que en la radical asunción de la ausencia de valores legítimos característica del nihilismo. En otras palabras: en el apartamiento de las desfiguraciones que ocultan dicha ausencia a través de la decidida renuncia a los valores ${ }^{86}$ que han convertido al hombre en esclavo de la técnica condenándolo bajo su hegemonía a la falta de libertad ${ }^{87}$.

Es en este punto donde finalmente se deja proponer la cuestión, y por más que Heidegger en ningún caso se ocupe de ella, sobre cuál sería la forma política o régimen estatal que podría corresponder al reconocimiento y difícil aceptación sin subterfugios del nihilismo y a su consecuente renuncia a los valores. Como se ha visto, Heidegger detecta en todas las formas políticas habidas históricamente-Estados parlamentarios y autoritarios, Estados liberales, comunistas o el Estado nacionalsocialista- ese recurso a los valores que lo enmascaran. Pero a sus análisis se ha de objetar que, si bien podrían acertar en lo relativo a los intentos de superación del Estado moderno que han representado los Estados fascistas y comunistas ${ }^{88}$, o quizá incluso a las realizaciones conocidas del mismo que habrían supuesto los llamados Estados democrático-liberales, no atienden al hecho de que algunos rasgos esenciales a la propia noción de Estado que nace y se va consolidando con el desarrollo de la modernidad no sólo muestran una evidente solidaridad con la maquinación como forma de presencia del ente específica de esta época, sino que también serían consistentes con el rechazo a la imposición de valores sobre una determinada colectividad ${ }^{99}$.

De entrada, cabe subrayar que la búsqueda de certeza y seguridad que subyace a la maquinación y, para Heidegger, suelo de lo político como concepto estrictamente moderno, presenta una coherencia interna con la idea de Estado de derecho como

\footnotetext{
${ }^{84}$ DGS, p. 197.

${ }^{85}$ Cfr. NII, p. 366 y ss.

${ }^{86}$ Cfr. M. Heidegger. Beiträge zur Philosophie, op. cit. p. 235.

${ }^{87}$ NII, p. 387.

${ }^{88}$ Cfr. F. Martínez Marzoa. «La palabra que viene», op. cit., pp. 154 y 157.

${ }^{89}$ Seguiremos a partir de aquí las consideraciones de F. Martínez Marzoa en su libro El concepto de lo civil (Santiago de Chile: Metales Pesados, 2008, p. 39 y ss.), en el que, a nuestro juicio, se parte de una idea de la presencia moderna del ente idéntica a la maquinación heideggeriana.
} 
sistema de garantías, esto es, como sistema en el que la legitimidad del poder político reside en su capacidad para garantizar o asegurar, a través de la universalidad de las leyes, que cada individuo pueda hacer todo aquello que sea compatible con la posibilidad de que cualquier otro, bajo las mismas condiciones, lo haga si así lo quiere. Concebida de este modo, esta noción de Estado presupone igualmente el reconocimiento de la ausencia de comunidad que resulta de la pérdida de la pólis griega: según se ha insistido a lo largo del trayecto recorrido, esa pérdida implica, en el orden de lo ontológico, la negación en las cosas de una naturaleza propia a partir de la cual se deduzcan pautas de conducta acerca de cómo proceder con ellas, negación de la que deriva la inviabilidad de proclamar la existencia de objetivos, fines o metas necesariamente comunes que sustenten la unidad orgánica de una comunidad. Pero esto concuerda plenamente con la plasmación del concepto moderno de Estado como sistema de garantías en un régimen de libertades individuales que asegure a cada cual la libre elección de cualesquiera fines que desee y en el que la única imposición legítima se ubica en la igual limitación de esa libre elección en aras de su propia garantía, es decir, para que el potencial choque entre la multiplicidad de fines de los distintos individuos no conlleve un estado de inseguridad respecto de su posible ejercicio. A todo ello se ha de añadir que, de tomarse en consideración que ningún concepto de derecho en tanto derecho igual tolera que las decisiones que afectan a todos sean tomadas al margen de la libre decisión de cada cual, esa misma garantía de libertades individuales demanda como tal el sufragio universal y, con él, todas las libertades políticas requeridas para su cumplimiento.

Nada más obvio que la constatación de que los Estados democráticos que a día de hoy más se aproximan a este modelo no han conseguido frenar la amenaza para el ser humano que Heidegger advierte en la maquinación. Antes bien, su surgimiento ha contribuido a consolidar y fomentar no sólo el producir por producir distintivo del régimen de producción capitalista, sino también la explotación, servidumbre y dominación abstracta ${ }^{90}$ a la que el hombre, tanto en la posición de explotado como en la de explotador, se ve sometido por causa de esa misma producción ilimitada. Pero si ante esta situación se juzga que ninguno de los Estados democráticos existentes hasta la fecha ha logrado materializar y hacer efectiva en sus trazos más elementales la noción de Estado que emerge en la modernidad en consonancia con el modo de manifestación de las cosas que designa la maquinación -y bajo cuyo «ineludible dominio» sería preciso según Heidegger instalarse conscientemente-, parece pertinente interrogarse sobre la validez del diagnóstico heideggeriano en lo que concierne al nihilismo imperante y a su enmascaramiento a través de la posición de valores. Lo que así se plantea es la pregunta acerca de si aquello que ha impedido y sigue coartando tal materialización no se hallaría, en efecto, en la apelación

\footnotetext{
${ }^{90}$ Cfr. P. Martínez Matías. «Producto y mercancía: sobre la constitución ontológica de la modernidad a partir de Heidegger y Marx». Logos. Anales del Seminario de Metafísica, vol. 47, 2014, p. 221.
} 
a ciertos valores que, por encubrir el estado de nihilidad que nos envuelve como modernos, imposibilitan su asunción. Como, por ejemplo, la libertad que en la actualidad y desde algunos sectores tan recurrentemente se reivindica como un valor $-\mathrm{y}$ no como una exigencia del contrato social-, pero antes reclamada para los mercados que para los individuos y por ello muy lejos de traducirse en cotas equiparables de libertad para todos los miembros de la sociedad. O, también, valores culturales de raigambre nacional que condenan a la acción política a la impotencia en el contexto de una economía globalizada. Pues tal vez pudiera suceder que un examen detenido de esta cuestión - tarea que ya desborda los objetivos de este trabajo- terminara por enfrentarnos a la circunstancia de que vivimos atenazados por esa angustia que Heidegger intuyera en la ocultación del nihilismo: la angustia ante la ausencia de metas y valores objetivamente vinculantes que, todavía a consecuencia de la ya remota e irreparable pérdida de Grecia, determinaría subrepticiamente la forma en que habitamos nuestro presente. 


\section{Bibliografía}

Arendt, H. Los origenes del totalitarismo. Madrid: Taurus, 1998.

Beistegui, M. de. Heidegger y lo político. Buenos Aires: Prometeo Libros, 2013.

Farías, V. Heidegger y el nazismo. Barcelona: Muchnik, 1989.

Faye, E. Heidegger. La introducción del nazismo en la filosofía. En torno a los seminarios inéditos de 1933-1935. Madrid: Akal, 2009.

Fried, G. Heidegger's Polemos. From Being to Politics. New Haven \& London: Yale University Press, 2000.

Fritsche, J. Historical Destinity and National Socialism in Heidegger's Being and Time. California: University of California Press, 2009.

Heidegger, M. Die Frage nach dem Ding. Tübingen: Niemeyer, 1987.

Heidegger, M. Parmenides. Frankfurt: Klostermann, 1992 (PA).

Heidegger, M. Hölderlins Hymne “Der Ister”. Frankfurt: Klostermann, 1993 (HHI).

Heidegger, M. Heraklit. Frankfurt: Klostermann, 1994.

Heidegger, M. Beiträge zur Philosophie (Vom Ereignis). Frankfurt: Klostermann, 1994.

Heidegger, M. Nietzsche II. Frankfurt, Klostermann, 1997 (NII).

Heidegger, M. Einführung in die Metaphysik. Tübingen: Niemeyer, 1998 (EM).

Heidegger, M. Die Geschichte des Seyns. Frankfurt: Klostermann, 1998 (DGS).

Heidegger, M. Hölderlins Hymnen "Germanien" und "Der Rhein". Frankfurt: Klostermann, 1999.

Heidegger, M. Vorträge und Aufsätze. Stuttgart: Neske, 2000.

Heidegger, M. Holzwege. Frankfurt: Klostermann, 2003.

Janicaud, D. L'ombre de cette pensé - Heidegger et la question politique. Grenoble: J. Millon, 1990.

Lacoue-Labarthe, P. La imitación de los modernos (Tipografias II). Buenos Aires: La Cebra, 2010.

Lacoue-Labarthe, P. La ficción de lo político. Madrid: Arena Libros, 2002.

Leyte, A. Heidegger. Madrid: Alianza, 2005.

Martínez Marzoa, F. «La palabra que viene», en Duque, F. (Comp.). Heidegger: la voz de tiempos sombrios. Barcelona: Serbal, 1991, pp. 147-160. 
Martínez Marzoa, F. El concepto de lo civil. Santiago de Chile: Metales Pesados, 2008.

Martínez Marzoa, F. La cosa y el relato. Madrid: Abada, 2009.

Martínez Matías, P. «Entre dioses y hombres: para una interpretación del problema de lo divino y lo sagrado en el pensamiento de Martin Heidegger». Anales del Seminario de Historia de la Filosofia, vol. 31, núm. 1, 2014, pp. 155-176.

Martínez Matías, P. «Producto y mercancía: sobre la constitución ontológica de la modernidad a partir de Heidegger y Marx». Logos. Anales del Seminario de Metafísica, vol. 47, 2014, pp. 199-225.

Míguez, A. «Comunidad y desarraigo: aproximación al fenómeno pólis». Isegoría, núm. 40, 2009, pp. 203-219.

Schmitt, C. «Weiterentwicklung des totalen Staates in Deutschland», en Positionen und Begriffe im Kampf mit Weimar-Genf-Versailles 1923-1939. Berlín: Dunker \& Humblot, 1994, pp. 211-216.

Schüermann, R. Le principe d'anarchie: Heidegger et la question de l'agir. París: Seuil, 1982.

Vietta, S. Heideggers Kritik am Nationalsozialismus und an der Technik. Tübingen: Niemeyer, 1989.

Zizek, S. En defensa de causas perdidas. Madrid: Akal, 2011. 